\title{
A conservação de áreas naturais e o Ecoturismo
}

\author{
The conservation of natural areas and the Ecotourism
}

\author{
André Scarambone Zaú
}

\begin{abstract}
RESUMO
Qual é o papel do Turismo sustentável e do Ecoturismo nas áreas protegidas? Quais devem ser os preparativos para eventos de grande porte como a Copa do Mundo e os Jogos Olímpicos? Como a Biologia da Conservação pode contribuir para o manejo do Turismo ambiental? Para lidar com essas questões, alguns importantes aspectos da Biologia da Conservação são global e regionalmente contextualizados. São discutidos os conceitos de "biodiversidade", "espécies comuns e raras", "população mínima viável", a necessidade de grandes espaços naturais para alguns organismos, bem como outros aspectos que levam a Conservação da Natureza a ser uma das questões mais importantes para a humanidade nos dias de hoje.
\end{abstract}

PALAVRAS-CHAVE: Parque Nacional; Turismo sustentável; Biologia da Conservação.

\section{ABSTRACT}

The role of sustainable tourism and ecotourism in protected areas will become of increased importance for the preparation of upcoming events like the Football World Cup and Olympic Games. Therefore, specific understanding of Conservation Biology should contribute to the management of environmental tourism. To address these issues, some important aspects of Conservation Biology in global and regional scales are contextualized. This paper discusses the concepts of "biodiversity", "common and rare species", "minimum viable population", the need for large natural areas for some organisms, as well as other aspects that make Conservation of Nature one of the most important issues for humanity today.

KEYWORDS: National Park; Sustainable Tourism; Conservation Biology.

\section{Introdução}

A conservação de áreas naturais envolve aspectos relacionados à preservação, conservação e uso dos espaços, sejam esses considerados "naturais" ou, em diferentes proporções, modificados pelo Homem. A conservação é fundamental para a sobrevivência de milhões de espécies e é essencial para a manutenção de funções dos ecossistemas que possibilitam qualidade de vida e a própria manutenção das sociedades (TERBORGH et al., 2002; RUDD, 2011; DIAMOND, 2012). 
Uma questão frequentemente levantada por conservacionistas está associada às atividades de turismo. O "turismo sustentável" pode contribuir efetivamente para a manutenção de locais "conservados", gerando renda de maneira perene e proporcionando melhoria da qualidade de vida de moradores dos arredores ou situados na área conservada (e.g. SEKERCIOGLU, 2002; DOUROJEANNI; PÁDUA, 2007; MINISTÉRIO DO MEIO AMBIENTE, 2011; BUENO et al., 2011). Mas, o turismo sustentável, especialmente o de base comunitária, pode ser também muito importante nos processos de educação, não apenas de turistas e frequentadores, como também para as populações locais (PEREIRA; CAMPOS, 2009; MACHADO, 2010). Além disso, pode ser muito importante como elemento de fiscalização, contribuindo para a conservação e recuperação de espaços naturais e culturas locais (TERBORGH et al., 2002; WEAVER; LAWTON, 2007; RAMCHURJEE, 2013). Por outro lado, o turismo também pode contribuir para a degradação ambiental (LAMB; WILLIS, 2011; BLERSCH; KANGAS, 2013), mesmo em suas formas mais idealizadas como o Ecoturismo (e.g. NELSON, 1994; BURGER et al., 1995; WALL, 1997; CARNEY; SYDEMAN, 1999; BLUMSTEIN et al., 2005; MATHESON et al., 2006; CHOMEL et al., 2007; PICKERING; HILL, 2007; BUCKLEY, 1994, 2012; WANG et al., 2012; COLLINS-KREINER et al., 2013). Dessa forma, atividades turísticas com planejamento e execução inadequados certamente irão contribuir para o empobrecimento ambiental e ecológico e para a pobreza econômica e sociocultural (e.g. VAN DYKE, 2008).

Trazer ao âmbito das Ciências relacionadas ao Turismo algumas questões de conhecimento específico, tratadas pela Ecologia e pela Conservação, bem como apresentar reflexões considerando a atual conjuntura de nossa sociedade é uma forma de difundir conhecimento (RODRIGUES; AMARANTE-JÚNIOR, 2009), contribuindo para 0 interdisciplinar (DONNELLY et al., 2011; WEAVER; LAWTON, 2007) e recente processo (WEAVER; LAWTON, op. cit.; NEIMAN et. al., 2010) de construção do conhecimento sobre Ecoturismo, Conservação e uso de espaços "naturais", cada vez mais importante nas sociedades atuais. Apesar disso, questões específicas relacionadas aos ambientes aquáticos, sejam eles continentais ou marinhos, não são abordadas nesse trabalho.

O mundo tem passado por significativas transformações sociais, econômicas e ecológicas nas últimas décadas (MILLENNIUM ECOSYSTEM ASSESSMENT, 2005; PARRY et. al. 2007). E, uma vez que algumas dessas modificações deverão ocorrer de forma ainda mais incisiva, pela própria sociedade, ou em função da promoção de eventos mundiais de massa, como a copa do mundo, olimpíadas, eventos religiosos, dentre outros - com base em princípios científicos da Biologia da Conservação - o objetivo dessa reflexão é também discutir concepções ideológicas para a conservação de áreas naturais, avaliando especialmente sua relação com o Ecoturismo. Espera-se, dessa forma, contribuir com a multiplicação de ideias, conceitos e ações que visem à efetiva conservação, em longo prazo, de algumas das áreas naturais de um dos países de maior biodiversidade do mundo (MINISTÉRIO DO MEIO AMBIENTE, 2012). 


\section{Áreas naturais (ainda) são importantes?}

\section{A natureza humana}

Algumas questões que evidenciam a importância da Natureza em termos gerais e, especialmente, a importância de "áreas naturais" para o Homem estão associados ao histórico evolutivo de nossa espécie. Dependíamos diretamente dos recursos que a natureza possibilitava como frutos e, posteriormente, caça (MORRIS, 2008). Antes de dominar o fogo e a agricultura éramos nômades e "fazíamos parte da Natureza". O Natural, o Sobrenatural e o Humano compunham um único Mundo. Porém, com a modificação do padrão nômade para o seminômade e, posteriormente para o sedentário, passamos a separar o meio "natural" do meio "humano". A partir daí, para continuar a utilizar e a modificar a Natureza, minimizando preocupações com possíveis consequências espirituais, "separamos" o mundo "natural" do "sobrenatural". Com isso passamos, de certa forma, a compensar o mundo "sagrado" através de oferendas e rituais liderados por sacerdotes que possibilitavam uma (re)ligação do mundo do Homem com o mundo sobrenatural (e.g. DIEGUES, 2001; VAN DYKE, 2008).

Entretanto, mesmo separados conceitual e fisicamente da natureza, nossas raízes não foram completamente esquecidas e nem podem ser desconsideradas. Durante o processo de evolução cultural de nossa espécie sentimos a necessidade de resgatar parte dessa natureza. Obviamente, essa nova natureza deveria ser selecionada, simplificada e segura para esse novo Homem. Construímos junto às moradias espaços de congregação (praças) para suprir a necessidade gregária de nossa espécie e, posteriormente criamos uma "natureza antrópica", baseada em jardins, parques urbanos, reservas de caça etc. (VAN DYKE, 2008). Desta forma, o contato com elementos da Natureza podia, por um lado, proporcionar contemplação e relaxamento e, por outro, apresentar os desejados desafios, porém, de forma controlada e segura. Em todos os casos, esse contato com a Natureza conduzia a prazeres associados à religação do Homem a aspectos de seu estado mais básico. Além disso, continuamos a ser elementos ativos na cadeia trófica, nos ciclos biogeoquímicos e no fluxo energético (BEGON et al., 2006), por exemplo, com nossa alimentação dependente de elementos naturais, domesticados ou não, e do uso essencial de elementos abióticos da natureza, como água, solo, nutrientes etc.

Atualmente benefícios associados à proximidade e à contemplação da Natureza são relacionados a melhores condições de vida e, consequentemente, à valorização de residências, bairros, cidades e países, através do processo de revalorização de espaços verdes (YANG et. al., 2009). Entretanto, a natureza que demanda mais preocupação dos conservacionistas na atualidade não é essa, mas aquela conhecida pela maior parte da sociedade, como "natureza selvagem".

\section{A importância da Natureza}

A importância de espaços "naturais" está ainda relacionada aos benefícios que a Natureza, ou melhor, que ecossistemas conservados (e.g. 
GIBSON et al., 2011) ou relativamente conservados e a própria biodiversidade (e.g. MYERS, 1996) proporcionam. A Avaliação Ecossistêmica do Milênio", instituída pela ONU, agrupou os "serviços ambientais" em quatro categorias: serviços de sustentação ambiental, como a formação de solos, a fotossíntese e a produção de oxigênio, a produção primária, a ciclagem de nutrientes e de água; serviços de regulação da qualidade do ar, do clima (temperatura e umidade), das águas (regulação das chuvas e controle de enchentes e secas), controle da erosão, purificação das águas, controle de doenças humanas e de pragas da agricultura, polinização, minimização de desastres naturais (como furacões e tsunamis); serviços de fornecimento de bens como alimentos derivados de plantas, animais e micro-organismos, fibras, combustível, recursos genéticos, compostos bioquímicos, medicina natural e fármacos, recursos ornamentais, água potável; e os serviços culturais, que incluem a diversidade cultural, valores espirituais e religiosos, conhecimentos tradicionais e formais, valores educacionais, de inspiração, estéticos, relações sociais, sentimento de pertencimento ao local, valores associados à herança cultural, recreação e ecoturismo (MILLENNIUM ECOSYSTEM ASSESSMENT, 2005).

Podemos ainda relacionar aqueles associados à opção de reserva para uso das próprias sociedades atuais ou futuras; sem esquecermos, é claro, de outros "valores" não associados ao uso, como por exemplo, o direito de cada espécie existir ou ainda o simples direito de conhecimento das espécies e dos ambientes (PRIMACK; RODRIGUES, 2001; HAMBLER, 2004).

Hoje conhecemos razoavelmente o "valor" da natureza e de sua conservação (e.g. PEREIRA; CAMPOS, 2009; MEDEIROS et al., 2011) e, apesar disso, o governo federal investe dez vezes mais para remediar desastres ambientais do que para preveni-los (MINISTÉRIO DO MEIO AMBIENTE, 2011).

Uma simples analogia dá uma dimensão ideológica de porque não devemos conservar a Natureza apenas associando-a as necessidades utilitaristas do ser humano. Segundo Hassanein (2000), se comprimirmos a idade da Terra (4,5 bilhões de anos) no intervalo de um ano, nossos ancestrais surgiram, no ano imaginário, no dia 31 de dezembro, às 20h. O Homem moderno surgiu na África, há 200 mil anos, às 23h 36mim. A civilização "organizada" surgiu às $23 \mathrm{~h}$ 56min e, às 24 horas nessa escala anual de tempo, ou em outubro de 2011 na escala temporal real, atingimos sete bilhões de habitantes (UN, 2011). Desta forma, podemos entender perfeitamente que a vida existe na Terra muito antes do surgimento do Homem.

Mesmo que, na conjuntura atual, cientistas apontem que sobreviverá apenas um percentual ainda incerto das espécies hoje existente (TERBORGH et al., 2002), e que 99,5\% dos cientistas da Conservação acreditem que a perda drástica da biodiversidade é possível, muito provável ou virtualmente certa (RUDD, 2011), vale frisar que, por sermos apenas uma dentre os milhões de espécies que ocorrem na Terra temos, ou pelo menos deveríamos ter, a consciência que outras espécies também necessitam de condições ambientais que permitam suas sobrevivências. 


\section{Mitos ou princípios científicos da Biologia da Conservação?}

Esse questionamento, pelo menos em parte, está associado ao debate sobre estratégias de conservação e uso de espaços, quando consideradas diferentes visões filosóficas, agrupadas nesse texto de maneira simplista em antropocêntricas e ecocêntricas (DIEGUES, 2001; TERBORGH et al., 2002). Porém, ao invés de discutir pontos positivos e negativos de cada enfoque, é mais apropriado discutir princípios básicos de uma recente e multidisciplinar área de estudo - a Biologia da Conservação (SOULÉ, 1985). Esses princípios estão relacionados à biodiversidade, ao número mínimo de organismos para populações saudáveis, a conceitos associados aos limites de funcionamento e estabilidade de ecossistemas e a efeitos que o crescimento populacional e o uso dos espaços pelo Homem.

\section{Biodiversidade: um conceito fundamental para a conservação}

A conscientização pública também será fundamental: desmistificar termos como biodiversidade e ecossistemas é um desafio. (SECRETARIADO DA CONVENÇÃO SOBRE DIVERSIDADE BIOLÓGICA, 2010, p. 6).

Detalhar e difundir conhecimentos ainda restritos a determinadas áreas da Ciência, como a Ecologia e a Biologia da Conservação, é essencial para o adequado manejo e gestão do Turismo ambiental, visto ser essa uma temática multidisciplinar.

Biodiversidade é definida como a variabilidade entre organismos vivos compreendendo ecossistemas terrestres, marinhos e outros ecossistemas aquáticos, considerando a diversidade dentro das espécies, entre espécies e de ecossistemas (SECRETARIADO DA CONVENÇÃO SOBRE DIVERSIDADE BIOLÓGICA, 2010). O conceito de biodiversidade considera a quantidade de espécies (riqueza) existentes em determinado local. Porém, também considera a proporção numérica (equitabilidade) entre os indivíduos das diferentes espécies que ocorrem/habitam tais localidades. Quando se avalia a biodiversidade de uma determinada área ela é denominada de " $\alpha$ "; quando se compara comunidades distintas: " $\beta$ "; dentro de uma paisagem: " $\gamma$ "; entre diferentes paisagens: " $\delta$ "; e, por fim, considerando uma grande região ou, um província biogeográfica: " $\varepsilon$ " (WHITTAKER et. al., 2001; WHITTAKER, 1972 apud MAGURRAN, 2013). A compreensão de tais atributos e considerações geográficas faz com que o uso do conceito de biodiversidade por profissionais da Conservação seja compreensível para outras áreas e seja, de fato, aplicável às ações de manejo e gestão ambiental.

O conceito de biodiversidade envolve ainda outras questões, como a diversidade genética, que pode ser entendida como aquela decorrente de variações genéticas entre indivíduos de uma espécie, os quais comporão uma ou mais populações; a diversidade filogenética, associada às relações de proximidade, ou não, de parentesco e às consequências que tais parentescos podem acarretar em termos de variabilidade de espécies; e 
a diversidade funcional, ligada à concepção de como espécies existentes num local podem ser associadas ao funcionamento do ecossistema (MAGURRAN, 2013).

Entretanto, ao invés de detalhar cada aspecto do conceito de biodiversidade é conveniente apresentar outras concepções também muito importantes para a Conservação. Algumas dessas têm sido tratadas como pressupostos, e até como princípios éticos ou ideológicos, uma vez que, mesmo sem um grande número de estudos empíricos conclusivos, as mesmas têm sido frequentemente relatadas como relevantes para a Conservação da Natureza (PRIMACK; RODRIGUES, 2001).

Uma justificativa facilmente compreensível para a necessidade de conservação da biodiversidade está associada às oportunidades de uso, estejam elas associadas ao uso direto, indireto ou potencial. Porém, outras questões relevantes como a da sustentabilidade dos ecossistemas deve ser abordada. Nesse sentido, a complexidade ecológica é considerada positiva (BEGON et al., 2006). Redundâncias ecológicas, ou seja, diferentes espécies realizando funções semelhantes em um mesmo espaço resultam em maior complexidade ecológica e em maior biodiversidade. Altas diversidades biológicas tendem a ser vistas como importantes, e algumas vezes fundamentais, para a perenidade, relativa estabilidade e/ou resiliência ${ }^{2}$ de ambientes naturais, quando resultam, por exemplo, em mais possibilidades de fluxos de energia ao longo de redes alimentares (BEGON et al., 2006). Entretanto, como em outros aspectos da Ecologia, nem sempre aquilo que supostamente é esperado corresponde à realidade. Ambientes simplificados também podem apresentar relativa estabilidade e ambientes complexos também podem ser frágeis, especialmente quando uma espécie-chave é afetada (WHITMORE, 1993).

Uma espécie é considerada "chave" para a comunidade quando sua presença localmente é mais relevante do que sua aparente quantidade (WHITMORE, op. cit.). Exemplificando, uma figueira ou uma palmeira da Mata Atlântica que frutifique em junho, julho e agosto - época na qual a maioria das espécies encontra-se em fase estéril - apresenta extrema relevância por sustentar parte da fauna durante um período crítico de carência alimentar. A exclusão ou o declínio significativo dessa espéciechave pode afetar a comunidade em proporções significativas, podendo até mesmo acarretar em desestruturação da comunidade original, a partir da extinção de várias espécies animais que dela dependem. Por sua vez, espécies animais deixando de existir localmente, afetam negativamente processos reprodutivos de várias outras espécies de plantas, por falta de polinização das flores, falta de eficiência na dispersão das sementes (REDFORD, 1992) ou ainda, pela ausência de controle adequado de espécies de herbívoros que as consomem (BROWN, 1987).

Entretanto, apesar da concepção mais conhecida que florestas tropicais úmidas são ecossistemas com baixa capacidade de recuperação, estudos indicam o contrário (e.g. SCARANO, 2006). Na Mata Atlântica ou no Cerrado, estudos sugerem que locais, mesmo empobrecidos em termos de biodiversidade de espécies nativas e até apresentando a ocorrência de espécies exóticas $^{3}$ (e.g. ABREU et. al., 2011), em alguma medida, conseguem se "recuperar". É descrito que essa recuperação se dá 
primeiramente (e às vezes exclusivamente) em termos de funcionalidade, antes mesmo de haver uma recuperação da biodiversidade propriamente dita (OLIVEIRA et al., 1994). Em parte, isso pode explicar processos de sucessão secundária observados na Mata Atlântica, apesar da intensa e longa influência antrópica (OLIVEIRA, 2005 e RIBEIRO et al., 2009)

Um terceiro e essencial aspecto em termos de "existência da vida", conforme conhecemos hoje é a evolução ou o processo evolutivo ("em biologia nada tem sentido, exceto à luz da evolução", Dobzhansky apud BEGON et al., 2006, p. v), assim como, "na biologia como um todo, poucas coisas têm sentido, exceto à luz da ecologia" (BEGON et al. op. cit., p. v). A evolução, e processos decorrentes da interação entre organismos que habitam extensas áreas de natureza "mais preservada" (alguns dos casos de áreas preservadas in-situ) estão associados à seleção natural. Consequentemente existe uma pressão natural que força a adaptação às condições do ambiente e resulta na eliminação ou na sobrevivência daqueles organismos mais adaptados, possibilitando a sobrevivência da espécie em longo prazo (FUTUYMA, 2009). O mesmo não ocorre em espaços de natureza antropizada, que abrigam plantas e animais, como jardins botânicos e jardins zoológicos, apesar da relevância dos mesmos para a conservação, considerando outros aspectos. Fora do ambiente natural (ex-situ) não existem, ou atuam de maneira distinta, as forças associadas à pressão seletiva (e.g. doenças naturais, predação, herbivoria, variações ambientais significativas, competição, facilitação etc). Soma-se o fato que esses indivíduos ex-situ, muitas vezes, não formam populações mínimas para perpetuação em longo prazo.

A mesma concepção que considera a evolução positiva para as espécies em longo prazo, segue o pressuposto que a extinção em larga escala, por razões de desequilíbrio antrópico, é negativa para a vida na Terra. Apesar de a extinção ser um processo natural, e de cerca de $99 \%$ das espécies que já existiram no mundo terem sido extintas em algum momento do passado em função de eventos catastróficos naturais (RAUP; SEPKOSKY, 1982); a extinção ocasionada pelo Homem é considerada extremamente negativa. Ações humanas dos últimos 30-50 mil anos transformaram a "Natureza" em uma "natureza com forte influência antrópica". Nos últimos milhares de anos fomos os responsáveis pela extinção de cerca de $80 \%$ da megafauna (animais com mais de $45 \mathrm{Kg}$ ). As ações realizadas especialmente pelo homem moderno, nos últimos 150 anos e, mais ainda, nos últimos 50 anos, foram responsáveis por uma taxa de extinção mil vezes mais alta que aquelas estimadas pelos registros fósseis (TERBORGH et al., 2002; MILLENNIUM ECOSYSTEM ASSESSMENT, 2005). Estima-se que sejam extintas cerca de 27 mil espécies por ano, ou seja, três espécies são extintas por hora! Já foram extintas cerca de $23 \%$ das espécies de aves e $20 \%$ das espécies de peixes foram extintas ou estão em franco declínio (DOUROJEANNI; PÁDUA, 2007). Infelizmente, a situação prevista é que as taxas de extinção no futuro sejam dez vezes maiores que as atuais (MILLENNIUM ECOSYSTEM ASSESSMENT, 2005).

A urgência de tratar dessas questões está associada ao fato que os serviços ecossistêmicos estão ameaçados pelo declínio da biodiversidade 
(SECRETARIADO DA CONVENÇÃO SOBRE DIVERSIDADE BIOLÓGICA, 2010). Esse mesmo documento afirma que serviços culturais, oportunidades de conhecimento e educação, valores recreativos e estéticos também estão sendo afetados pela perda da Biodiversidade.

\section{Conhecimento ou desconhecimento sobre a Biodiversidade?}

Ao contrário do que pensa a grande maioria das pessoas, 0 homem já extinguiu, sim, a maior parte das espécies de grande porte que encontrou neste planeta. Os povos que hoje dizemos que coexistem em harmonia com a natureza coexistem apenas com as espécies difíceis de extinguir, porque as fáceis já foram exterminadas há muito tempo (FERNANDEZ, 2005, p. 5).

Entretanto, apesar de sermos executores, da maior onda de extinções de toda a história, não temos o conhecimento real de tudo o está sendo extinto nem de todas as possibilidades que estamos perdendo (FERNANDEZ, 2004).

A diversidade biológica pode ser agrupada por níveis de organização. O primeiro é chamado de "pool genético" ou bagagem genética que cada espécie apresenta. Em termos gerais, quando maior a bagagem genética, mais possibilidades de responder às mudanças que se apresentam durante o processo de seleção natural. Consequentemente existirão mais possibilidades de sobreviver às adversidades que surgem no meio, como suportar anos muito secos, muito úmidos, variações significativas no clima ocasionadas por mudanças climáticas (THOMAS, 2010), ou possibilitar a sobrevivência de indivíduos que geneticamente apresentam maior resistência à determinada bactéria ou vírus, por exemplo (FUTUYMA, 2009).

O segundo nível está associado às populações. Quanto mais variadas as distintas populações de uma mesma espécie e quanto mais populações existirem, maiores serão as chances de sobrevivência da espécie. As vantagens de comunidades com mais diversidade e de ecossistemas mais diversos estão associadas, conforme relatado, às oportunidades e à maior estabilidade ecológica.

Em termos gerais, especialmente as florestas tropicais e os recifes de corais, são caracterizados como detentores dos maiores índices de biodiversidade (CONNEL, 1978). As florestas tropicais, que cobrem cerca de $7 \%$ da superfície terrestre, abrigam cerca de $50 \%$ das espécies conhecidas no mundo (WHITMORE, 1993). Entretanto, quando falamos de conhecimento sobre a biodiversidade deveríamos, na verdade, falar de desconhecimento sobre a biodiversidade.

Nosso conhecimento sobre a biodiversidade mundial é bastante restrito. São conhecidas aproximadamente 1 milhão e 800 mil espécies em todo o mundo (MINISTÉRIO DO MEIO AMBIENTE, 2011). Entretanto, o número total de espécies pode estar entre 5 e 10 milhões (MAGURRAN, 2013) ou ainda em torno de 5 a 30 milhões (DOUROJEANNI; PÁDUA, 
2007). Se estimarmos um número intermediário, por exemplo 10 milhões, no início do século 21 conhecemos menos de $20 \%$ das espécies do Mundo! O nosso desconhecimento é bastante maior quanto consideramos aspectos ecológicos ou bioquímicos de espécies, estejam elas dentre as conhecidas ou ainda desconhecidas pela Ciência.

Nesse cenário, o Brasil, uma das regiões da terra com maior biodiversidade (BROOKS et al., 2006), detém cerca de 11,4\% da biodiversidade do planeta, sendo que 5,5\% desta está na Amazônia, o que equivale a quase $50 \%$ da biodiversidade de todo o país (MINISTÉRIO DO MEIO AMBIENTE, 2012).

Obviamente, apesar desse desconhecimento, a conservação da biodiversidade é fundamental, tanto para conservação de oportunidades como para a manutenção das redes de relacionamento e de interconexões entre espécies, comunidades e ecossistemas - em última instância, ambientes que determinam a qualidade de recursos como água, ar e solos, essenciais à qualidade e mesmo à sobrevivência de sociedades (PRIMACK; RODRIGUES, 2001; DIAMOND, 2012).

\section{Populações mínimas e a necessidade de (grandes) espaços}

Uma população mínima viável pode ser descrita de forma simples como a menor população que apresenta $99 \%$ de chances de existir numa escala temporal de 1.000 anos (PRIMACK; RODRIGUES, 2001). Genericamente, e de forma bastante simplificada, na natureza, animais ou plantas necessitam de populações com, no mínimo, números que estimados em cerca de 30-50 indivíduos para perpetuarem por poucas gerações, durante um curto prazo, ou seja, dez anos, considerando indivíduos com ciclo de vida relativamente longo. Para perpetuação por muitas gerações, ou por 100 anos ou mais, são necessários cerca de 500 indivíduos da espécie. Essa é a denominada "regra dos 50/500" (SHAFFER, 1981; SOULÉ, 1986). Tal restrição tem razões biológicas que não cabem ser aprofundadas aqui. Mas, é facilmente entendida quando transportamos esse "problema" para nossa espécie.

No passado, reis e nobres casavam com parentes próximos para manter as riquezas e não dividir seus reinos. Como os descendentes com problemas genéticos eram atribuídos ao "pecado" das relações com parentes, foram criadas regras sociais para impedir a união entre parentes próximos (PIMENTEL, 2007). Obviamente, uma simples reflexão nos fará perceber que o "problema da consanguinidade" também ocorre com outras espécies, além da nossa.

Quando pensamos em escala evolutiva, para perpetuação de espécies, são necessárias pelo menos entre três a cinco populações de 500 ou mais indivíduos cada. Para determinadas espécies normalmente "raras" na natureza, como árvores com densidades extremamente baixas e predadores de topo da cadeia alimentar, isso pode demandar mais de 1 milhão hectares (i.e. PRIMACK; RODRIGUES, 2001; TERBORGH et al., 2002; DOUROJEANNI; PÁDUA, 2007). 
Relacionando essa limitação biológica aos espaços naturais, podemos entender que nem todos os espaços naturais restantes (na verdade poucos deles) apresentam condições adequadas para perpetuação de espécies com as características supracitadas. Entretanto, para espécies comuns e/ou muito abundantes, áreas relativamente pequenas podem ser suficientes para sobrevivência. Áreas de tamanho reduzido, como pequenos fragmentos de paisagens "naturais" podem suportar organismos comuns na natureza. Porém, não suportam organismos de espécies raras, que necessitam de grandes espaços, ou que vivem em ambientes com características muito restritas.

Mega herbívoros e carnívoros de topo de cadeia alimentar não têm condições de se manter vivos, em longo prazo, em paisagens fragmentadas ou significativamente transformadas. Pior ainda se estiverem em áreas com um determinado nível de presença antrópica. Para esses organismos são necessárias grandes áreas naturais, sem a permanência e com baixa ou praticamente nenhuma presença antrópica (TERBORGH et al., 2002). Em parte, por concepções diferentes quando consideramos valores das sociedades, várias espécies de mamíferos e aves foram extintas pelo Homem nos últimos mil anos (FERNANDEZ, 2005).

Podemos exemplificar a situação acima citada a partir de três elementos de fácil compreensão. O palmito Jussara (Euterpe edulis), a onça pitada (Panthera onca) e o Parque Nacional da Tijuca. O PARNA Tijuca é o mais visitado do Brasil, com cerca de 2,5 milhões de visitantes por ano e tem cerca de 4 mil hectares (MINISTÉRIO DO MEIO AMBIENTE, 2008) (um hectare equivale aproximadamente a um campo de futebol). Considerando que no parque o palmito pode apresentar uma densidade de até 500 indivíduos por hectare (ZAÚ, 2010), e que a área conta com aproximadamente 1.100-1.200 ha em bom estado de conservação (COELHO-NETTO et al., 2007), esse espaço seria plenamente suficiente para que o palmito tivesse uma população de mais de 500 mil indivíduos! Certamente, os números efetivos são muito mais baixos, em função da existência de trechos razoavelmente preservados, mas que não apresentam características ecológicas (hábitats) específicos para ocorrência do palmito. Entretanto, essa ordem de grandeza forma um bom ponto de partida para que a espécie possa ter uma população devidamente preservada nessa unidade de conservação. Obviamente devem ainda ser consideradas também a necessidade de conservação das outras espécies associadas à ecologia do palmito, como seus polinizadores e dispersores.

Entretanto, quando consideramos o caso da onça, os resultados idealizados são bastante distintos. Uma onça-pintada com uma cria pode demandar de 2 a 5 mil ha (DOUROJEANNI; PÁDUA, 2007). Desta forma, um mesmo parque que pode ser eficaz para a conservação do palmito, pode não o ser para espécies muito raras, mega herbívoros ou carnívoros de topo de cadeia alimentar. Afinal, nesse caso, ter um indivíduo de onça no parque, do ponto de vista biológico, seria semelhante a ter essa onça presa em um jardim zoológico, cercada por paredes e grades. E, ainda, neste caso específico, muito menos seguro para ela e para a gente, em função do "pequeno tamanho" do parque, de seu contexto eminentemente urbano e 
dos dois milhões e meio de visitantes por ano (MINISTÉRIO DO MEIO AMBIENTE, 2008).

Mesmo que alguns desses princípios não estejam completamente definidos, testados e comprovados de forma absolutamente irrefutável (alguns dos quais talvez nunca o sejam por que nem sempre podermos criar modelos precisos ou mesmo generalizar situações quando tratamos de ecossistemas complexos), a conservação de áreas restantes ainda em bom estado de conservação deveria no mínimo seguir o princípio da precaução, ou seja,

...a garantia contra os riscos potenciais que, de acordo com o estado atual do conhecimento, não podem ser ainda identificados. Este Princípio afirma que na ausência da certeza científica formal, a existência de um risco de um dano sério ou irreversível requer a implementação de medidas que possam prever este dano (GOLDIM, 2002, $\mathrm{s} / \mathrm{p})$.

\section{É possível conservar populações e espécies ameaçadas na Mata Atlântica?}

Semelhantemente ao número de organismos e espaços mínimos que as populações demandam para serem viáveis em longo prazo, os processos de perpetuação e recuperação dos espaços naturais, que se dão por meio da sucessão ecológica, são dependentes dos espaços e da densidade de indivíduos das espécies. Ou seja, eles dependem da saúde ecológica das populações, que por sua vez dependem do tamanho e da proximidade de ambientes que podem funcionar como repositórios eventuais ou esporádicos de organismos (ZAÚ, 1998).

A Mata Atlântica, em função de suas características geográficas (MORELLATO; HADDAD, 2000) e de historicidade (DEAN, 1997), apresenta importantes condicionantes em termos de conservação. Dentre eles, se destacam: 1) o alto grau de degradação do Bioma, tanto em relação à superfície remanescente no Brasil (88,3\% da cobertura original perdida, restando $11,7 \%{ }^{4}$ da cobertura original), quanto em relação aos altos percentuais de fragmentação da vegetação remanescente, na qual $83,4 \%$ dos fragmentos têm menos de 50 ha e $97 \%$ menos de 250 ha (RIBEIRO et al., 2009); 2) a alta riqueza e o alto endemismo (STEHMANN et al., 2009) que, associados ao alto grau de degradação, caracterizam a Mata Atlântica como um dos ecossistemas prioritários em termos de conservação (MYERS et al., 2000; BROOKS et al., 2006); e 3) o fato de que no domínio da Mata Atlântica, coexiste $67 \%$ da população brasileira, cerca de 120 milhões de habitantes, distribuídos em 61\% (3400) dos municípios do país (PINTO et al., 2006). Obviamente o gerenciamento do Bioma, nesse contexto, é um enorme desafio.

A fragmentação florestal é considerada uma das principais ameaças à biodiversidade (SAUNDERS et al., 1991). Na conjuntura de superfícies cada vez mais transformadas e urbanizadas, tanto 
mundialmente, como no $\mathrm{Brasil}^{5}$, aumenta a importância e, principalmente, a necessidade de estratégias para a conservação, tanto em termos de paisagem (e.g., SANTOS et al., 2008), como de áreas naturais próximas ou mesmo localizadas nas cidades (JIM; CHEN 2009). Nestes casos, os benefícios indiretos (e.g., ULRICH, 1986; TYRVÄINEN; VÄÄNÄNEN, 1998) e diretos (e.g., BOLUND; HUNHAMMAR, 1999 e YANG et al., 2009) da manutenção da biodiversidade e das funções ecossistêmicas (GARDNER et al., 2010) assumem significativo impacto, até mesmo quando consideradas as florestas inseridas em grandes cidades (KONIJNENDIJK, 2003). Tais benefícios são resultado da conservação da biodiversidade local como elemento de conexão entre áreas naturais, pela facilidade de observação frente à mudanças ambientais, relevância nas ações de educação ambiental, serviços ambientais à população local, questões associadas à responsabilidade ética e ambiental, ou mesmo pelo bem estar humano (DEARBORN; KARK, 2009). Essa é a situação do PARNA Tijuca, o mais visitado do Brasil e aquele que abriga uma das maiores florestas urbanas do mundo (MINISTÉRIO DO MEIO AMBIENTE, 2008), com os benefícios e conflitos decorrentes da circunvizinhança de uma megacidade.

A situação crítica da Mata Atlântica pode ser mais bem delimitada quando apresentamos alguns números. Dos fragmentos restantes, $83 \%$ deles possuem menos que 50 ha (20\% do total) e $92 \%$ menos que 100 ha (30\% do total) (RIBEIRO et al., 2009). Considerando o tamanho mínimo adequado de 5.000 ha (GALINDO-LEAL; CÂMARA, 2005) para unidades de conservação na Mata Atlântica que objetivem a preservação da biodiversidade em longo prazo, certamente o Bioma já está seriamente ameaçado. Especialmente para o caso de espécies naturalmente raras, superexploradas, para os mega herbívoros e para os carnívoros de topo da cadeia alimentar. Como consequência, temos em várias localidades processos que resultam em florestas vazias com extinção em cadeia ou cascata (REDFORD, 1992). Para dimensionar a interdependência entre organismos e porque os processos de extinção podem se dar de forma generalizada, estudos apontam que é extremamente alto (até 90\%) o percentual das espécies arbóreas nos ambientes tropicais cujas sementes são espalhadas por animais (e.g., HOWE; SMALLWOOD, 1982). Na ausência desses, o processo de perpetuação dessas espécies vegetais fica bastante comprometido.

Mesmo no contexto generalizado de degradação da paisagem, quando uma região se estabelece como "pólo turístico", a valorização e, consequentemente, a manutenção de pequenos trechos florestados apresenta significativa relevância ecológica. Porém, é importante que esses trechos de mata apresentem relativa conectividade ou ligação com outros fragmentos. No caso da Mata Atlântica o isolamento ou a distância média entre os fragmentos está em torno de $1.400 \mathrm{~m}$ (RIBEIRO et al., 2009). Essa distância pode ser considerada significativamente alta para ser transposta por uma série de organismos. Entretanto, sem os "fragmentos pequenos" (< 50 ha) a distância de isolamento sobe para $3.500 \mathrm{~m}$. E, sem os fragmentos "médios" (< 200 ha) essa distância atinge 8.000m (RIBEIRO et al., op. cit.). Ou seja, a falta de conectividade entre fragmentos florestais dificulta a reposição eventual de organismos naqueles fragmentos com piores 
condições de conservação, e desfavorece a conservação na região em longo prazo. Dessa forma, o turismo, como mecanismo para conservação de paisagens naturais, resulta em benefícios adicionais, além daqueles diretos ao setor (e.g. WEAVER; LAWTON, 2007; WALTER, 2013).

Em termos de vizinhança dos fragmentos em relação a outros ambientes, $73 \%$ dos fragmentos encontram-se a menos de $250 \mathrm{~m}$ de áreas abertas, $46 \%$ a menos de $100 \mathrm{~m}$ e somente menos de $8 \%$ encontram-se a mais de $1000 \mathrm{~m}$ de áreas abertas (RIBEIRO et al., op. cit.). A proximidade dos remanescentes com áreas abertas favorece a degradação, seja pela ação humana direta ou indireta, decorrente dos efeitos de borda. Novamente, a concepção do pólo turístico pode favorecer a conservação local.

Associados à fragmentação, os efeitos de borda estão dentre as questões mais relevantes (LAURANCE, 1991; MALCOLM, 1994; MURCIA, 1995). Eles podem ser caracterizados como decorrentes de alterações físicas e biológicas nos contatos da floresta com trechos alterados (KAPOS, 1989; ZAÚ, 1998; HARPER et al., 2005). Estudos conduzidos em bordas de florestas tropicais frequentemente caracterizam diferenciações e gradientes borda-interior em relação a condições microambientais, estrutura vegetal, composição biótica e interações (e.g. LAURANCE, 1991; CAMARGO; KAPOS, 1995; MURCIA 1995; LAURANCE; BIERREGAARD, 1997; BIERREGAARD et al., 2001). Ações de manejo e valorização dos princípios da conservação associados ao turismo também podem ter ação positiva aqui.

Entretanto, resumidamente, no caso da Mata Atlântica, para espécies raras, endêmicas, ou, exemplificando novamente o caso da onça-pintada um animal do topo de cadeia - para conter cerca de 500 indivíduos seriam necessárias grandes áreas que ultrapassam os $10.000 \mathrm{~km}^{2}$ ou 1 milhão de hectares, em boas condições de conservação. Assim, por exemplo, onças e animais semelhantes não existirão mais em populações saudáveis na Mata Atlântica, à exceção de alguns poucos trechos contínuos de florestas, na Serra do Mar, e em Missiones, na Argentina (GALINDO-LEAL; CÂMARA, 2005).

\section{Reflexões para a conservação em longo prazo}

Se acreditarmos que a Natureza pode ser preservada apenas em espaços destinados às áreas protegidas, estaremos cometendo equívoco fatal para nossa geração, para as gerações futuras e para a vida na Terra (TERBORGH et al., 2002; DOUROJEANNI; PÁDUA, 2007). Porém, as Unidades de Conservação (UC) são consideradas os instrumentos mais eficientes para a conservação da biodiversidade (e.g. TERBORGH et al., op. cit.; DOUROJEANNI; PÁDUA, op. cit.; MINISTÉRIO DO MEIO AMBIENTE, 2011). Estudos indicam que processos de extinção em UC de porte médio (400 mil hectares) podem levar quatro mil anos antes de atingir entre $60 \mathrm{e}$ 80\% das espécies iniciais (WILCOX, 1980 apud. DOUROJEANNI; PÁDUA, op. cit.). Por isso, são indicadas pelos especialistas em conservação mais UC de uso indireto, como Parques Nacionais e Reservas Biológicas, e que essas sejam de tamanhos maiores que os supracitados. Tem sido sugerido 
também que o conjunto de UC não contenha menos de $10 \%$ dos ecossistemas em bom estado de conservação, e idealmente $30 \%$ ou mais (DOUROJEANNI; PÁDUA, op. cit.), com o objetivo de incluir uma parcela significativa da biota local, preservando 0 maior percentual de biodiversidade possível. Nesse contexto, se o objetivo for preservar espécies predadoras que ocorrem em baixas densidades populacionais, o tamanho mínimo recomendado para uma unidade de conservação deveria ser, pelo menos, 100 mil ha (SOULÉ; COX, 1980 apud. DOUROJEANNI; PÁDUA, 2007, pág. 73).

Alguns dos princípios comentados anteriormente podem ser sintetizados através do triplo "C" da conservação (SOULÉ, 1986; SOULÉ, 2000 apud. DOUROJEANNI; PÁDUA, 2007): carnívoros, core ou áreas centrais sem efeitos de borda e conectividade entre áreas protegidas. Desta forma, UC de uso de grande porte, de uso restrito, sem presença constante do ser humano (i.e. moradores em seu interior ou visitantes frequentes), e conectadas através de trechos com proteção legal permanente, como margens de rios, topos de morros etc. (ZAÚ, 1997) representam as condições adequadas e mesmo necessárias para que realmente esses princípios da conservação possam ser alcançados em longo prazo.

Em termos conservacionistas, o ideal são mosaicos regionais de megareservas (maiores que um milhão de hectares), interconectadas por áreas menos conservadas, sob diferentes graus de proteção, de maneira a considerar a integração entre esses espaços (TERBORGH et al., 2002). Somente desta forma poderemos preservar onças-pintadas, onças-pardas, cachorros-do-mato, mono-carvoeiros, lontras, jequitibás, castanheiras etc. A gestão considerando os princípios da Biologia da Conservação e da Ecologia da Paisagem é a única forma de preservar fenômenos ecológicos em larga escala, como migrações de peixes e mudanças sazonais de hábitats de frugívoros (TERBORGH et al., op. cit.).

Buscando formular estratégias complementares em termos de conservação de comunidades e ecossistemas, e do uso de espaços com características naturais o Sistema Nacional de Unidades de Conservação (SNUC, 2000) organiza as UC brasileiras em dois grandes grupos: proteção integral, que supostamente visa à preservação (i.e. Estação Ecológica, Reserva Biológica, Parque Nacional, Monumento Natural, Refúgio de Vida Silvestre); e uso sustentável, que visa o uso e, supostamente, a conservação da natureza (i.e. Área de Proteção Ambiental, Área de Relevante Interesse Ecológico, Floresta Nacional, Reserva Extrativista, Reserva de Fauna, Reserva de Desenvolvimento Sustentável e Reserva Particular do Patrimônio Natural.

O SNUC, em associação com outros dispositivos legais, tem sido um mecanismo importante em termos conservacionistas, especialmente no contexto macroeconômico de valorização de formas de desenvolvimento insustentáveis.

As Áreas de Preservação Permanentes (APP) (e.g. topos de morros, margens de rios, encostas com declividades superiores a $45^{\circ}$ ) e as Reservas Legais (RL) (i.e. percentuais de terra destinados à conservação e 
manutenção de condições ecossistêmicas e dos serviços ambientais), alocadas em terras rurais privadas cobrem, respectivamente, $12 \%$ e $30 \%$ do território nacional, correspondendo, no total, a mais que o dobro da área atualmente coberta por unidades de conservação (MINISTÉRIO DO MEIO AMBIENTE, 2011). Infelizmente, mesmo sem as futuras perdas decorrentes das modificações no código florestal (LEI № 12.651; 2012), em 2010, 42\% das APP e 16,5\% das RL já apresentavam desmatamentos ilegais (MINISTÉRIO DO MEIO AMBIENTE, 2011).

Não cabe aprofundar as diferenças ou adequações de cada tipo de UC, porém, vale registrar que para efetiva preservação, as UC de proteção integral, especialmente os Parques Nacionais e as Reservas Biológicas, são consideradas as mais eficientes em longo prazo (DOUROJEANNI; PÁDUA, 2007).

\section{Áreas protegidas no mundo e no Brasil: quanto "protegemos"?}

Dados de 2008 apontavam que o Brasil estava em $16^{\circ}$ no ranking (Tabela 1), em termos de percentual de território destinado às "áreas protegidas" (senso IBGE, 2011). Dentre os países da América do Sul, o Brasil aparece em $3^{\circ}$ (Tabela 2). Entretanto, como os dados originais não puderam ser acessados seguindo a fonte indicada, não foi possível definir com clareza os critérios que definiram o conceito de "área protegida" adotado oficialmente.

Tabela 1: Percentual de território nacional com área protegida (senso IBGE, 2011). Dados de 2008, considerando os países primeiros colocados no ranking.

Table 1: Percentage of national territory with protected area (sense IBGE, 2011). 2008 data, considering the countries ranking in the first places.

\begin{tabular}{clcl}
\hline Ordem & \multicolumn{1}{c}{ País } & $\%$ & \multicolumn{1}{c}{ Continente } \\
\hline 1 & Venezuela & 65,7 & América do Sul \\
2 & Alemanha & 54,4 & Europa \\
3 & Zâmbia & 41,1 & África \\
4 & Liechtenstein & 40,1 & Europa \\
5 & Tanzânia & 37,8 & África \\
6 & Arábia Saudita & 36,8 & Oriente Médio \\
7 & Brunei & 32,4 & Sudeste Asiático \\
8 & Estônia & 31,1 & Europa \\
9 & Guiné-Bissau & 31,0 & África \\
10 & Guatemala & 31,0 & América Central \\
11 & Estados Unidos & 30,6 & América do Norte \\
12 & Colômbia & 30,3 & América do Sul \\
13 & Belize & 30,2 & América Central \\
14 & Botswana & 30,1 & África \\
15 & Israel & 29,1 & Oriente Médio \\
16 & Brasil & 28,9 & América do Sul \\
\hline
\end{tabular}


Tabela 2: Percentual de território nacional com área protegida (senso IBGE, 2011). Dados de 2008, considerando os países da América do Sul.

Table 2: Percentage of national territory with protected area (sense IBGE, 2011). 2008 data, considering the countries of South America.

\begin{tabular}{clr}
\hline Ordem & \multicolumn{1}{c}{ País } & $\%$ \\
\hline 1 & Venezuela & 65,7 \\
2 & Colômbia & 30,3 \\
3 & Brasil & 28,9 \\
4 & Bolívia & 21,2 \\
5 & Equador & 15,1 \\
6 & Chile & 14,0 \\
7 & Peru & 13,2 \\
8 & Suriname & 13,2 \\
9 & Argentina & 6,2 \\
10 & Paraguai & 6,0 \\
11 & Guiana & 2,2 \\
12 & Uruguai & 0,3 \\
\hline
\end{tabular}

Entretanto, considerando dados de 2010, no Brasil existem 1.963 unidades de conservação as quais, juntas com as terras indígenas e áreas identificadas como importantes para a conservação da biodiversidade, totalizam 3.190 "áreas protegidas" (MINISTÉRIO DO MEIO AMBIENTE, 2011). Esses números podem parecer altos, entretanto considerando o território de um dos países mais biodiversos do mundo, eles são insuficientes para a conservação da biodiversidade.

Estabelecemos em 2006, na Convenção da Diversidade Biológica, a meta de proteger com unidades de conservação pelo menos $30 \%$ da Amazônia e $10 \%$ dos outros biomas. Naquele ano, as unidades de conservação terrestre cobriam $8 \%$ do território nacional. Em 2010, o percentual de território protegido em UC, por Bioma, estava distribuído da seguinte forma: Amazônia (27,1\%), Caatinga $(7,3 \%)$, Cerrado $(8,4 \%)$, Mata Atlântica $(9,0 \%)$, Pampa (3,5\%), Pantanal $(4,8 \%)$ e ambientes costeiros e marinhos (3,1\%) (MINISTERIO DO MEIO AMBIENTE, 2011).

Porém, conforme discutido, os percentuais considerados mais relevantes para a preservação da biodiversidade são aqueles limitados às UC de proteção integral. Provavelmente a situação a seguir está mais próxima daquela efetiva em termos de conservação da biodiversidade no Brasil. Na Amazônia estão supostamente "protegidos integralmente" cerca de $9,4 \%$ de seu território" ${ }^{\prime \prime}$, na Caatinga $1,0 \%$, no Cerrado 2,5\%, na Mata Atlântica 2,0\%, nos Pampas 0,8\%, no Pantanal 2,2\% e nos ambientes costeiros e marinhos $0,3 \%$ (MINISTÉRIO DO MEIO AMBIENTE, op. cit.). Obviamente, esses percentuais são insuficientes para a conservação de nossa rica biodiversidade. Conforme exposto, se acreditarmos que a Natureza deve ou pode ser preservada apenas em espaços destinados às "áreas protegidas", cometeremos um equívoco irreversível. Sem contar com o fato que, várias áreas supostamente protegidas dentro dos critérios mais restritivos do SNUC, por exemplo, Parques Nacionais e Reservas 
Biológicas, por vezes não conseguem exercer suas funções mais básicas conservação da biodiversidade - à longo prazo, por falta de pessoal para fiscalização e aplicação dos instrumentos legais em relação à ocupação dos espaços e pressões antrópicas insustentáveis (DOUROJEANNI; PÁDUA, 2007).

De forma resumida, pode-se dizer que, no mínimo, a aplicação do princípio da precaução e dos princípios da Biologia da Conservação deve ser realizada considerando o SNUC e a legislação conexa. Isso é fundamental para a Conservação da Natureza em nosso país.

\section{Conservação de áreas naturais e o "Ecoturismo"}

\section{O papel do Turismo sustentável e do Ecoturismo nas UC}

O turismo é uma das mais prósperas atividades econômicas do mundo (DOUROJEANNI; PÁDUA, 2007). Dentro de um perfil que adota e valoriza o ambiente natural, o Ecoturismo, setor crescente dentro do Turismo (MATHESON et. al. 2006.) é frequentemente apresentado como um dos poucos exemplos de "desenvolvimento sustentável", uma vez que pode auxiliar a conservação in situ das áreas naturais e gerar retorno econômico direto (DAVENPORT; RAO, 2002). Entretanto, conforme visto, mesmo o Ecoturismo causa algum impacto. Ainda mais quando realizado de forma não regulamentada, superintensiva ou sem a avaliação de impactos gerados pela visitação. Ele pode causar degradação ambiental e inviabilizar, inclusive financeiramente, o próprio turismo e outras atividades econômicas associadas à conservação da área (e.g. DAVENPORT; RAO op. cit.; SYNAI, 2007; LAMB; WILLIS, 2011), uma vez que essa indústria ainda não incorporou importantes requisitos para a sustentabilidade (BUCKLEY, 2012).

O planejamento do uso de UC é realizado através do plano de manejo. Um plano adequado deve conter um zoneamento que objetive a conservação em longo prazo. E a implementação deste é fundamental para a realização de uma proposta de visitação ecologicamente sustentável (MALTA; COSTA, 2009). Planos de manejo que abordem o Turismo são essenciais (SANTOS, 2011), por exemplo, para Parques Nacionais ou Estaduais uma vez que esse tipo de UC tem como

\footnotetext{
objetivo básico a preservação de ecossistemas naturais de grande relevância ecológica e beleza cênica, possibilitando a realização de pesquisas científicas e o desenvolvimento de atividades de educação e interpretação ambiental, de recreação em contato com a natureza e de turismo ecológico (Art. 11, Lei 9.985 - SNUC, 2000).
}

A execução do sistema de zoneamento é um dos primeiros e mais importantes passos para implementação de um parque e para aplicação de sua proposta de manejo do turismo (DAVENPORT; RAO, 2002). Um bom zoneamento envolve a ponderação de metas que, de certa forma, podem 
ser conflitantes entre si (DAVENPORT; RAO, 2002); além de possibilitar que mecanismos de gestão sejam devidamente implementados e possam gerar avaliações concretas sobre o manejo aplicado, tanto no interior da UC como nos arredores.

O zoneamento adequado para a visitação delimita trechos nos quais a mesma deve ser incentivada, por exemplo, pela valorização de aspectos cênicos, de grande interesse ecológico ou cultural, pela construção de equipamentos públicos como praças, ruas, estacionamentos, centros de informações para visitantes, alojamentos, banheiros, campings, dentre outras; além de estruturas aplicadas diretamente à experiências mais intensivas, como trilhas rústicas, placas de sinalização distantes dos equipamentos públicos anteriormente relacionados.

Também devem ser considerados trechos nos quais a visitação deve ser desestimulada e até mesmo restringida (e.g. BURGER et. al. 1995), de forma temporária ou permanente. Como justificativa para restrição permanente, poderíamos exemplificar o caso de alguns trechos de mais difícil acesso e/ou que apresentem características ecológicas com condições ambientais mais adequadas para sobrevivência e reprodução de espécies da flora e fauna; ou ainda trechos com populações de espécies raras e/ou ameaçadas de extinção.

Como exemplo de restrição temporária poderíamos citar o fechamento de trilhas ou pontos de visitação em determinadas épocas do ano associadas à reprodução de espécies animais, ou ainda a eventos climáticos que possam acarretar em um grau de risco não adequado aos visitantes, como aqueles decorrente de períodos de chuvas mais intensas, enchentes, deslizamentos ou desmoronamentos. No processo de zoneamento, sempre a primeira consideração deve ser a conservação dos hábitats e, para isso, a atenção cuidadosa aos princípios da Biologia da Conservação deve ser priorizada na tomada de decisões (DAVENPORT; RAO, 2002).

Nesse contexto, aumenta ainda mais a relevância do planejamento e execução de ações de gestão turística nas Unidades de Conservação. Essas devem seguir os aspectos definidos nos planos de manejo, considerando limitações de acesso em áreas restritas, as quais, especialmente em situações de maior fluxo de visitantes, podem ser "indevidamente" frequentadas por turistas com perfil mais "aventureiro". Ou ainda aquelas áreas que por sua relevância ambiental ou relativa fragilidade ecológica, mesmo estando inseridas em um contexto de visitação mais frequente ou intensa, necessariamente terão que passar por um processo de ampliação de mecanismos de controle e fiscalização. Dessa forma, por exemplo, avaliações de capacidade de carga associadas à projetos de Educação ambiental passam a ser ferramentas fundamentais para a garantia da conservação dos hábitats.

Podemos ainda dimensionar a necessidade de uma proposta de manejo e gestão apropriada, considerando, por exemplo, um aspecto de grande relevância natural ou cultural e o contexto da paisagem estética e funcional em uma UC de proteção integral. A estátua do Cristo Redentor do Rio de Janeiro, inserida no Parque Nacional da Tijuca é considerada uma 
das sete maravilhas do mundo moderno (FOLHA ONLINE, 2007). Recebe mais de 2,5 milhões de visitantes por ano (MINISTÉRIO DO MEIO AMBIENTE, 2008), mas, certamente, não é somente a estátua do Cristo que atrai os turistas. A essência da contemplação e da exaltação por parte dos turistas é reflexo também do impacto que a paisagem proporciona. A vista de parte da cidade cercada, por um lado, por íngremes montanhas cobertas por Mata Atlântica em bom estado de conservação (ZAÚ, 2010) e, por outro, delimitada pelo mar e pelo céu, compõe o cenário que, indiscutivelmente, faz desse conjunto uma das "maravilhas" do mundo. A estátua do Cristo em outra localidade, sem a vista da "cidade maravilhosa", sem suas montanhas cobertas por florestas e sem a vista do litoral e do mar, certamente não atrairia tantos turistas... Assim, o zoneamento deve contemplar os intensos fluxos para esse ponto, mas também deve considerar que esse apelo existe por causa do conjunto inseparável da paisagem.

Um ecoturismo minimamente sustentável do ponto de vista ecológico deve ser pautado em atividades responsáveis e pressões que não resultem em significativos prejuízos às condições necessárias à conservação da flora e da fauna. Ou, na impossibilidade disto, os gestores devem priorizar ações que restrinjam os impactos à determinados locais, de maneira a não afetar significativamente as populações, a comunidade e o ecossistema. Para isso, existem alguns procedimentos que podem auxiliar na gestão de parques. Dentre eles podemos citar a avaliação e gestão da "capacidade de carga", da qual são reconhecidos diferentes tipos como a capacidade de carga física do local; a capacidade de carga associada à capacidade de recebimento da equipe do parque e a capacidade de carga social, ou seja, o número máximo de visitantes de forma não diminuir a experiência positiva da visitação (DAVENPORT; RAO, 2002).

Alguns indicadores podem ser utilizados para aferição da capacidade de carga. Podemos citar a frequência de encontros com outros visitantes; a erosão e a compactação de trilhas; a qualidade da água; alterações na estrutura física da vegetação nas proximidades de trilhas, áreas de lazer, acampamentos; a abundância de espécies sensíveis, indicadoras, exóticas, quantidade de lixo, dentre outros (DAVENPORT; RAO, 2002; COSTA et al., 2008; CONCEIÇÃO et al., 2010).

Além dos Parques (Nacionais, Estaduais e Municipais) existem outros tipos de UC que podem e receber turistas e ecoturistas. Dentre as UC de proteção integral destaca-se a categoria "Monumento Natural", pelos objetivos e atributos naturais, não desconsiderando outros tipos. Dentre aquelas de uso sustentável, sugere-se o estímulo à visitação em Áreas de Proteção Ambiental mais conservadas, Reservas Extrativistas e Reservas de Desenvolvimento Sustentável (desde que compatível com os interesses locais e de acordo com o disposto no plano de manejo da área) e Reservas Particulares do Patrimônio Natural.

Certamente a visitação associada às atividades de recreação e lazer em contato com a natureza, turismo ecológico, e educação e interpretação ambiental promove a valorização dos espaços naturais visitados e de espaços similares. Além disso, é uma forte aliada dos mecanismos de fiscalização (DOUROJEANNI; PÁDUA, 2007) e promove, de maneira prática, princípios gerais associados à valorização da Natureza (i.e. 
valorização direta e indireta de funções dos ecossistemas e da biodiversidade, valorização da qualidade de vida e de aspectos da origem antrópica, do respeito a outras formas de vida etc.) (TERBORGH et al., 2002); podendo ainda ser uma significativa fonte de renda sustentável, econômica e ecologicamente (PEREIRA; CAMPOS, 2009). Mas, é essencial a realização de um planejamento crítico, com investimentos compatíveis, com base científica, e que considere não somente aspectos sociais e econômicos mais imediatos, como também os princípios da conservação em longo prazo, para não corrermos o risco de repetirmos a fábula da "galinha dos ovos de ouro".

\section{Preparativos para os próximos anos? Grandes eventos no Brasil}

O Rio de Janeiro tem passado por significativos incrementos em termos de visitação em razão de grandes eventos como encontros religiosos, Copa do Mundo e, em 2016, as Olimpíadas. Parte desse incremento de visitação se manterá após os grandes eventos, tanto nas áreas listadas na tabela 3, como em outras.

Tabela 3: Unidades de conservação existentes no Estado do Rio de Janeiro nas quais é provável o significativo incremento de visitantes durante os eventos da Copa do Mundo, em 2014 e das Olimpíadas, em 2016.

Table 3: Protected Areas in the State of Rio de Janeiro where it is likely the significant increase of visitors during the events of the World Cup in 2014 and the Olympic Games in 2016.

\begin{tabular}{lrcr}
\hline \multicolumn{1}{c}{ Unidade de conservação } & Área (mil ha) & Esfera & Fonte \\
\hline Parque Nacional da Tijuca & 4 & Federal & MMA, 2011 \\
Parque Nacional da Serra do Órgãos & 10 & 28 \\
Parque Nacional do Itatiaia & 98 & \\
Parque Nacional da Serra da Bocaina & 15 & \\
Parque Nacional da Restinga de Jurubatiba & 12 & Estadual & INEA, 2011 \\
\hline Parque Estadual da Pedra Branca & 15 & \\
Parque Estadual da Ilha Grande & 38 & \\
Parque Estadual de Cunhambebe & &
\end{tabular}

Monumento Natural dos Morros do Pão de

Açúcar e Urca

0,09 Municipal PCRJ, 2006

Obs.: "Dos Parques Nacionais que apresentam estrutura de visitação, em 2009, foram registrados cerca de 3,9 milhões de visitantes. Porém, 70\% desse total se concentraram no PARNA da Tijuca (RJ) e no PARNA do Iguaçu (PR) (MEDEIROS, et al., 2011)."

É fundamental esse processo de aprofundamento da questão por parte dos gestores governamentais, uma vez que os parques relacionados na tabela 4 foram avaliados como prioritários para o recebimento dos investimentos de divulgação turística (BRASIL, 2013). Nesse contexto, 
considerando o documento anteriormente citado que aponta que "Os grandes eventos que o Brasil sediará, entre elas a Copa do Mundo de 2014, e as Olimpíadas de 2016, aparecem como um dos focos do programa. $A$ intenção é atrair, para as unidades de conservação, os turistas que visitarão - País durante os eventos.", e que "Até 2020, 69 parques nacionais brasileiros serão abertos à visitação."; esses parques devem ter seus planos de manejo atualizados, especialmente no que se refere aos cuidados necessários para a ampliação da visitação turística com qualidade. $\mathrm{E}$, obviamente, que essa visitação seja realizada com a restrita manutenção das condições ambientais que permitem a efetiva conservação da biodiversidade.

Tabela 4: Parques Nacionais que receberão investimentos para incremento de visitantes a partir de 2014 (Copa do Mundo) e 2016 (Olimpíadas).

Table 4: National Parks that will receive investments to increase visitors from 2014 (World Cup) and 2016 (Olympics Games).

\section{Parque Nacional - Estado(s)}

Parque Nacional de Anavilhanas - Amazonas

Parque Nacional dos Lençóis Maranhenses - Maranhão

Parque Nacional de Jericoacoara - Ceará

Parque Nacional de Ubajara - Ceará

Parque Nacional Marinho de Fernando de Noronha - Pernambuco

Parque Nacional da Chapada Diamantina - Bahia

Parque Nacional da Brasília - Distrito Federal

Parque Nacional da Chapada dos Guimarães - Mato Grosso

Parque Nacional da Chapada dos Veadeiros - Goiás

Parque Nacional da Serra do Cipó - Minas Gerais

Parque Nacional da Tijuca - Rio de Janeiro

Parque Nacional da Serra dos Órgãos - Rio de Janeiro

Parque Nacional de Itatiaia - Minas Gerais/Rio de Janeiro

Parque Nacional do Iguaçu - Paraná

Parque Nacional de Aparados da Serra - Rio Grande do Sul/Santa Catarina

Parque Nacional da Serra Geral - Rio Grande do Sul/Santa Catarina

Certamente, os benefícios econômicos advindos do turismo naqueles parques mais visitados devem ajudar a proteger os mesmos e, como também outras áreas ${ }^{7}$ de fundamental importância para a conservação, como importantes reservas biológicas e os mega parques nacionais, todos de grande relevância conservacionista, considerando os princípios da Biologia da Conservação anteriormente explicitados (Tabela 5).

Os impactos derivados dos grandes eventos não podem ser baseados no princípio da particularização dos lucros e socialização dos prejuízos. Os serviços ambientais e a biodiversidade são bens comuns da comunidade local, da região, do país, da humanidade e, bens associados à existência da vida. Não podem ser superexplorados por grupos de pessoas, empresas, governos, superorganizações, megaeventos ou qualquer outra entidade. A possibilidade de geração de um grande montante financeiro diretamente gerado pelo Turismo ambiental lato sensu ou do Ecoturismo não pode ser motivo para concessões de manejo e gestão que 
comprometam de forma significativa, ou mesmo definitiva, os principais objetivos das UC, sejam elas de proteção integral ou uso sustentável.

Tabela 5: Os dez maiores Parques Nacionais do Brasil.

Table 5: The ten largest National Parks in Brazil.

\begin{tabular}{lrc}
\hline \multicolumn{1}{c}{ Mega parques brasileiros } & Área (mil ha) & Estado \\
\hline PARNA Montanhas do Tumucumaque & 3 milhões e 882 mil ha & AP \\
PARNA do Jaú & 2 milhões e 378 mil ha & AM \\
PARNA do Pico da Neblina & 2 milhões e 262 mil ha & AM \\
PARNA da Amazônia & 1 milhão e 117 mil ha & AM/PA \\
PARNA do Jamanxim & 864 mil ha & PA \\
PARNA da Serra do Divisor & 841 mil ha & AC \\
PARNA das Nascentes do Rio Parnaíba & 733 mil ha & MA/TO/PI/BA \\
PARNA de Pacaás Novos & 711 mil ha & RO \\
PARNA do Cabo Orange & 660 mil ha & AP \\
PARNA do Araguaia & 558 mil ha & TO \\
\hline
\end{tabular}

A geração de renda, direta ou indireta dos serviços ambientais, originadas das UC superam significativamente 0 montante que tem sido destinado pelas administrações públicas à manutenção do Sistema Nacional de Unidades de Conservação da Natureza (MEDEIROS et al., 2011, p. 6).

Ainda segundo Medeiros et al. (op. cit., p. 7)

a visitação nos 67 Parques Nacionais existentes no Brasil tem potencial para gerar entre $R \$ 1,6$ bilhão e $R \$ 1,8$ bilhão por ano, considerando as estimativas de fluxo de turistas projetadas para o país (cerca de 13,7 milhões de pessoas, entre brasileiros e estrangeiros) até 2016, ano das Olimpíadas (MEDEIROS et al., op. cit., p. 7) e,

Considerando as tendências atuais de crescimento de número de visitantes a unidades de conservação, os investimentos direcionados às unidades de conservação federais e estaduais nos últimos anos e as perspectivas de investimentos, inclusive as decorrentes da Copa 2014 e Olimpíadas 2016, é possível vislumbrar um cenário promissor para o impacto econômico da visitação nestas áreas. Um aumento de entre 15 e $25 \%$ no número de visitantes até 2016 resultaria em um fluxo de aproximadamente 20 milhões de turistas nas 698 unidades federais e estaduais consideradas pelo estudo, com um impacto na economia dessas regiões estimado entre $R \$ 1,9$ bilhão e R $\$$ 2,2 bilhões, em 2016 (MEDEIROS et al., 2011, p. 25). 
Dessa forma, para que essa resultante econômica potencial seja efetivada ao final de cada grande evento é necessário que as unidades de conservação tenham os investimentos necessários e estejam prontas para receber os visitantes (MEDEIROS, et al., 2011). A regularização fundiária, e a elaboração ou atualização dos planos de manejo das UC é de grande importância para o sucesso dos programas, especialmente nos aspectos relacionados ao turismo. Ou seja, implementação do zoneamento para visitação, instalação de equipamentos públicos, como banheiros, espaços para congregação, formação de equipes suficientes e preparadas para recepção dos turistas, manutenção de trilhas e pontos de visitação; além de transporte, segurança, guias preparados, sistema de hospedagem, dentre outros, compõem aspectos multifacetários do Turismo ambiental sustentável.

\section{Considerações finais: como a Biologia da Conservação pode contribuir para a gestão do Turismo ecologicamente sustentável?}

A manutenção dos atributos ecológicos e das condições ambientais das áreas protegidas deveriam ser prioritárias na sociedade. A razão é que essas áreas são essenciais para a conservação da biodiversidade. Entretanto, sabemos que as mesmas por si não são suficientes para proteger a biodiversidade. Locais não inseridos em unidades de conservação ou inseridos em unidades de conservação de uso sustentável também são muito importantes. Sabemos ainda que, em tese, quanto maior e mais preservada a área, melhor para a conservação e que a conectividade entre áreas e a manutenção de processos ecológicos é essencial para a perpetuação das populações em longo prazo (TERBORGH et al., 2002). Esses são princípios que devem ser adotados pelos gestores e divulgados para a sociedade.

Passado quase meio século, numa conjuntura de crescimento demográfico mundial distinto daquele previsto, pelo menos em alguma medida, e apesar de discordâncias radicais a respeito das possíveis soluções para problemas decorrentes de usos de espaços públicos, não podemos deixar de associar a concepção da "tragédia dos comuns", de Hardim (1968), às áreas naturais. Isso se dá especialmente quando relacionamos a pouca relevância política dada a ações que conduzam à efetiva conservação, especialmente em parques nacionais, reservas biológicas e estações ecológicas, áreas consideradas, de modo geral, as de maior relevância para a conservação. E, caso parques nacionais continuem a funcionar sem a devida infraestrutura, legalização das terras, com indenizações justas, ou ainda, caso os mesmos estejam abertos a variadas formas de uso, legal ou ilegal, ao acesso indiscriminado a quaisquer trechos, por mais significativos que os mesmos sejam para a conservação de suas espécies, processos ecológicos ou atributos que justificaram suas implementações legais; estaremos incidindo na "tragédia dos comuns". Esse processo é decorrente de ações individuais ou coletivas, por vezes não intencionais, que afetam negativamente, muitas vezes de forma lenta, mas contínua, características que justificaram que essas áreas se tornassem unidades de conservação. Obviamente são necessárias ações efetivas para o controle do uso; recepção dos turistas; estabelecimento de estrutura física 
adequada; e montagem e permanência de equipes suficientes e qualificadas para atuar na gerência, fiscalização, pesquisa e atendimento aos usuários. $\mathrm{E}$, nesse contexto, a gestão do uso deverá estar baseada em bioindicadores de impacto antrópico, devendo ser essa uma das prioridades no manejo.

Num contexto de grandes modificações sociais e ambientais são fundamentais ações sociais e políticas, além do desenvolvimento de atividades econômicas que efetivamente sejam sustentáveis em longo prazo, inclusive do ponto de vista ecológico. Assim, o uso de áreas naturais protegidas, especialmente de parques nacionais, com atividades relacionadas ao Turismo, seja ele de massa ou Ecoturismo, deve estar baseado no conhecimento, em estudos de capacidade de carga, em resultados e dados básicos de pesquisas científicas ou, na ausência desses, no princípio da precaução.

Devemos, junto com a valorização dos espaços naturais, estimular a responsabilidade social, a educação ambiental crítica, comprometida socialmente, e a prática de ações que impeçam com que aquilo que hoje buscamos de forma direta ou recebemos indiretamente da Natureza seja negativamente modificado. Esse é o papel do cidadão consciente, na difícil luta para a efetiva Conservação da Natureza.

\section{Referências bibliográficas}

ABREU, R.C.R.; ASSIS, G.B.; FRISON, S.; AGUIRRE, A; DURIGAN, G. Can native vegetation recover after slash pine cultivation in the Brazilian Savanna? Forest Ecology and Management, Amsterdam, v. 262, n. 8, p. 1452-1459, 2011.

BEGON, M.; TOWNSEND, C.R.; HARPER, J.L. Ecology: from individuals to ecosystems. Oxford: Blackwell Publishing, 2006. 738 p.

BIERREGAARD Jr. R.O.; GASCON, C.; LOVEJOY, T.E. ; MESQUITA, R.C.G. (Eds.). Lessons from Amazonia: the ecology and conservation of a fragmented forest. Michigan: Sheridan Books, 2001. $475 \mathrm{p}$.

BLERSCH, D.M.; KANGAS, P.C. A modeling analyses of the sustainability of ecotourism in Belize. Environment, Development and Sustainability. Oxford: v. 15, p. 67-80, 2013.

BLUMSTEIN, D.T.; FERNANDEZ-JURICIC E.; ZOLLNER P.A.; GARITY S.C. Inter-specific variation in avian responses to human disturbance. Journal of Applied Ecology, London, v. 42, n. 5, p. 943-953, 2005.

BOLUND, P.; HUNHAMMAR, S. Ecosystem services in urban areas. Ecological Economics, Amsterdam, v. 29, p. 293-301, 1999.

BROOKS, T.M; MITTERMEIER, R.A.; FONSECA, G.A.B.; GERLACH, J.; HOFFMANN, M.; LAMOREUX, J. .; MITTERMEIER, C. .; PILGRIM, J. .; RODRIGUES, A.S.L. Global biodiversity conservation priorities. Science, Washington, v. 313, p. 58-61, 2006.

BROWN Jr., K.S. O papel dos consumidores na conservação e no manejo de recursos genéticos florestais in situ. IPEF, São Paulo, n. 35, p. 61-70, 1987.

BUCKLEY, R. A Framework for Ecotourism. Annals of Tourism Research, v. 21, n. 3. p. 661-669. 1994. 
BUCKLEY, R. Sustainable tourism: Research and reality. Annals of Tourism Research, v. 39, n. 2, p. 528-546, 2012.

BUENO, C; PARDO, F.B.L.; REIFF, F P.; VINHA, V. Ecoturismo responsável e seus fundamentos. $1^{\underline{a}}$ ed. Rio de Janeiro: Technical Books, 2011. 256 p.

BURGER, J., GOCHFELD, M., NILES, L.J. Ecotourism and birds in coastal New Jersey: Contrasting responses of birds, tourists, and managers. Environmental Conservation, Cambridge, v. 22, n. 1, p. 56-65, 1995.

CAMARGO, J.L.C.; KAPOS, V. Complex edge effects on soil moisture and microclimate in central Amazonian forest. Journal of Tropical Ecology, Cambridge, n. 11, p. 205-221, 1995.

CARNEY, K.M.; SYDEMAN, W.J. A review of human disturbance effects on nesting colonial waterbirds. Waterbirds, British Columbia, v. 22, n. 1, p. 68-79, 1999.

CHOMEL, B.B.; BELOTTO, A.; MESLIN, F.-X. Wildlife, exotic pets, and emerging zoonoses. Emerging Infectious Diseases, Atlanta, v. 13, n. 1, p. 611, 2007.

COELHO-NETTO, A.L.; AVELAR, A.S.; FERNANDES, M.C.; LACERDA, W.A. Landslide susceptibility in a mountainous geoecosystem, Tijuca Massif, Rio de Janeiro: The role of morphometric subdivision of the terrain. Geomorphology, Manhattan, v. 87, p. 120-131, 2007.

COLLINS-KREINER, N.; MALKINSON, D.; LABINGER, Z.; SHTAINVARZ, R. Are birders good for birds? Bird conservation through tourism management in the Hula Valley, Israel. Tourism Management, v. 38, p. 31-42, 2013.

CONCEIÇÃO, R.S.; COSTA, N.M.C.; COSTA, V.C. A importância da evolução do uso do solo como geoindicador para o planejamento do Ecoturismo em Unidades de Conservação: aplicação no Parque Estadual da Pedra Branca (RJ). Revista Brasileira de Ecoturismo, São Paulo, v. 3, n. 3, p. 408-427, 2010.

CONNEL, J.H. Diversity in tropical rain forests and coral reefs. Science, Washington, v. 199, p. 1302-1310, 1978.

COSTA, V.C.; TRIANE, B.P.; COSTA, N.M.C. Impactos ambientais em trilhas: agricultura X Ecoturismo - um estudo de caso na Trilha do Quilombo (PEPBRJ). Revista Brasileira de Ecoturismo, São Paulo, v. 1, n. 1, p.84-113, 2008.

DAVENPORT, L.; RAO, M. A História da Proteção: Paradoxos do Passado e Desafios do Futuro. In. TERBORGH, J.; SCHAIK, C.; DAVENPORT, L.; MADHU, R. Tornando os parques eficientes - estratégias para a conservação da natureza nos trópicos. Curitiba: Editora da UFPR / Fundação O Boticário, 2002. p. 52-73.

DEAN, W. A ferro e fogo. História e devastação da Mata Atlântica brasileira. São Paulo: Companhia das Letras, 1997. 484 p.

DEARBORN, D.C.; KARK, S. Motivations for Conserving Urban Biodiversity. Conservation Biology, Malden, v. 24, n. 2, p. 432-440, 2009.

DIAMOND, J. Colapso. Tradução de Alexandre Raposo. $8^{\mathrm{a}}$ ed. Rio de Janeiro: Record, 2012. 699 p.

DIEGUES, A.C. O Mito Moderno da Natureza Intocada. 4. ed. São Paulo: Hucitec; NUPAUB/USP, 2004. 169 p. 
DONNELLY, R.E.; KATZNER, T.; GORDON, I.J.; GOMPPER, M.E.; REDPATH, S.; GARNER, T.W.J.; ALTWEGG, R.; REED, D.H. ACEVEDO-WHITEHOUSE, $\mathrm{K}$; PETTORELLI, N. Putting the eco back in ecotourism. Animal Conservation, v. 14, p. 325-327. 2011.

DOUROJEANNI, M.J.; PÁDUA, M.T.J. Biodiversidade: a hora decisiva. $2^{\underline{a}}$ ed. Curitiba: UFPR, 2007. 282 p.

FERNANDEZ, F.A.S. O Poema Imperfeito: Crônicas de Biologia, Conservação da Natureza e Seus Heróis (2 ${ }^{a}$ edição). Curitiba: Editora da Universidade Federal do Paraná/Fundação O Boticário de Proteção à Natureza, 2004. 260 p.

FERNANDEZ, F.A.S. Aprendendo a lição de Chaco Canyon: do "Desenvolvimento Sustentável" a uma Vida Sustentável. Reflexão. São Paulo, v. 6, n. 15, 2005.

FOLHA ONLINE. 2007. Cristo Redentor é eleito uma das sete novas maravilhas do mundo. Disponível em $<$ http://www1.folha.uol.com.br/folha/ilustrada/ult90u310220.shtml de 07/07/2007 - 19h17>. Acesso em: 10 set. 2011.

FUNDAÇÃO SOS MATA ATLÂNTICA e INSTITUTO NACIONAL DE PESQUISAS ESPACIAIS. Atlas dos remanescentes florestais da Mata Atlântica - período 2008-2010. Dados parciais dos Estados avaliados até maio de 2010. São Paulo, 2010. 60 p.

FUTUYMA, D.J. Biologia evolutiva. $3^{\mathrm{a}}$ ed. Ribeirão Preto: FUNPEC, 2009. 631 p.

GALINDO-LEAL, C.; CÂMARA, I.G. (Ed.). Mata Atlântica: biodiversidade, ameaças e perspectivas. Belo Horizonte: Fundação SOS Mata Atlântica, 2005. $472 p$.

GARDNER, T.A.; BARLOW, J.; SODHI, N.S.; PERES, C.A. A multi-region assessment of tropical forest biodiversity in a human-modified world. Biological Conservation, Barking, v. 143, n. 10, p. 2293-2300. 2010.

GIBSON, L.; LEE, T. M.; KOH, L.P. ; BROOK, B.W.; GARDNER, T.A.; BARLOW, J.; PERES, C.A. BRADSHAW, C.J.A.; LAURANCE, W.F.; LOVEJOY, T.E.; SODHI, N.S. Primary forests are irreplaceable for sustaining tropical biodiversity, Nature, Londres, v. 478. p. 378-381, 2011.

GOLDIM, J.R. O Princípio da Precaução, 2002. Disponível em: <http://www.ufrgs.br/bioetica/precau.htm>. Acesso em: 07 set. 2011.

HAMBLER, C. Conservation. Cambridge: Cambridge University Press, 2004. $368 \mathrm{p}$.

HARDIM, G. The tragedy of the commons. Science, Washington, v. 162, n. 13. 1243-1248. 1968.

HARPER, K.A.; MACDONALD, S.E.; BURTON, P. .; CHEN, J.; BROSOFSKE, K. D.; SAUNDERS, S. .; EUSKIRCHEN, E. .; ROBERTS, D.; JAITEH, M. .; ESSEEN, P. . Edge influence on forest structure and composition in fragmented landscapes. Conservation Biology, Malden, v. 19, n. 3, p. 768-782, 2005.

HASSANEIN, S. The History of Planet Earth, 2000. Disponível em: <http://www.arabworldbooks.com/articles10.htm >. Acesso em: 14 abr. 2009.

HOWE, H.F.; SMALLWOOD, J. Ecology of seed dispersal. Annual Review of Ecology and Systematics, Amsterdam, v. 13, p. 201-228, 1982. 
IBGE, 2011. Países@. $\quad$ Disponível em $<$ http://www.ibge.gov.br/paisesat/main.php $>$. Acesso em: 11 abr. 2011 (Base primária dos dados: "Summary of protection by country and territory on the 31st January 2008. In: World Database on Protected Areas. New York: United Nations Environment Programme, World Conservation Monitoring Centre, 2008").

JIM, C.Y.; CHEN, W.Y. Ecosystem services and valuation of urban forests in China. Cities, Los Angeles, v. 26, n. 3, p. 187-194, 2009.

KAPOS, V. Effects of isolation on the water status of forest patches in the Brazilian Amazon. Journal of Tropical Ecology, Cambridge, v. 5, n. 2, p. 173185, 1989.

KONIJNENDIJK, C.C. A. Decade of urban forestry in Europe. Forest Policy and Economics, Finland, v. 5, n. 2, p. 173-186, 2003.

LAMB, J.B.; WILLIS, B.L. Using Coral Disease Prevalence to Assess the Effects of Concentrating Tourism Activities on Offshore Reefs in a Tropical Marine Park. Conservation Biology, Malden, v. 25, n. 5, p. 1044-1052, 2011.

LAURANCE, W.F. Edge effects in tropical forest fragments: applications of a model for the design of nature reserves. Biological Conservation, Barking, v. 57, p. 205-219, 1991.

LAURANCE, W.F.; BIERREGAARD, R.O. Tropical forest remnants: Ecology, Management, and Conservation of fragmented communities. Chicago: The University of Chicago Press, 1997. $616 \mathrm{p}$.

MACHADO, R. Proposições Conservadora e Crítica em Educação Ambiental: a discussão das duas possibilidades em um mesmo espaço. Revista Brasileira de Ecoturismo, São Paulo, v. 3, n. 1, p.23-46, 2010.

MAGURRAN, A. Medindo a diversidade biológica. Tradução de Dana Moiana Vianna. Curitiba: UFPR, 2013. 261 p.

MALCOLM, J.R. Edge Effects in Central Amazonian Forest Fragments. Ecology, Washington/DC, v. 75, n. 8, p. 2438-2445, 1994.

MALTA, R.R.; COSTA, N.M.C. Gestão do Uso Público em Unidade de Conservação: a visitação no Parque Nacional da Tijuca - RJ. Revista Brasileira de Ecoturismo, São Paulo, v. 2, n. 3, p. 273-294, 2009.

MATHESON, M.D.; SHEERAN, L.K.; LI, J.H.; WAGNER, R.S. Tourist impact on Tibetan macaques. Anthrozoos, Cambridge, v. 19, n. 2, p. 158-168, 2006.

MEDEIROS, R.; YOUNG, C.E.F.; PAVESE, H.B.; ARAÚJO, F.F.S. (Ed.) Contribuição das unidades de conservação brasileiras para a economia nacional: Sumário Executivo. Brasília: UNEP-WCMC, 2011. 44 p.

MILLENNIUM ECOSYSTEM ASSESSMENT - 2005. Ecosystems and Human Well-being: Biodiversity Synthesis. World Resources Institute, Washington, DC, 2005. 100 p. Disponível em: < http://www.maweb.org/en/index.aspx >. Acesso em: 07 set. 2011.

MINISTÉRIO DO MEIO AMBIENTE. 2008. Instituto Chico Mendes de Conservação da Biodiversidade. Plano de manejo: Parque Nacional da Tijuca. Brasília, DF, 30 abr. 2008. 548 p. Disponível em: <http://www.parquedatijuca.com.br/manejo.php>. Acesso em: 29 out. 2012. 
MINISTÉRIO DO MEIO AMBIENTE. 2011. Quarto relatório nacional para a convenção sobre diversidade biológica: Brasil. Brasília: MMA, 2011. 248 p. MMA (Ministério do Meio Ambiente: http://www.mma.gov.br/>. Acesso em: 29 out 2012.

MINISTÉRIO DO MEIO AMBIENTE. 2012. Megadiversidade em foco. Disponível em $<$ http://blog.mma.gov.br/biodiversidade2010/2010/07/13/megadiversidade-emfoco/>. Acesso em: 29 out 2012.

MORELLATO, L.P.C.; HADDAD, C.F.B. Introduction: The Brazilian Atlantic Forest. Biotropica, Oxford, v. 32, n. 4b, p. 786-792, 2000.

MORRIS, D. O macaco nú. Rio de Janeiro: Record, 2008. 270 p.

MURCIA, C. Edge effects in fragmented forests: implications for conservation. Trends in Ecology and Evolution, Oxford, v. 10, n. 2, p. 58-62, 1995.

MYERS, N. Environmental services of biodiversity. Proceedings of the National Academy of Sciences of the United States of America, Washington, v. 93, n. 7, p. 2764-2769, 1996.

MYERS, N.; MITTERMEIER, R.A.; MITTERMEIER, C.G.; FONSECA, G.A.B.; KENT, J. Biodiversity hotspots for conservation priorities. Nature, Londres, $v$. 403, p. 853-858, 2000.

NEIMAN, Z.; SARACENI, R. F.; GEERDINK, S. Levantamento quali-quantitativo da produção científica sobre Ecoturismo no Brasil. Revista Brasileira de Ecoturismo, São Paulo, v.3, n.3, p.528-555, 2010.

NELSON J.G. The spread of ecotourism: Some planning implications. Environmental Conservation, Cambridge, vol. 21, n. 3, p. 248-255, 1994.

OLIVEIRA, R.R. (Org.). As marcas do homem na floresta: História ambiental de um trecho de Mata Atlântica. Rio de Janeiro: PUC-Rio, 2005. 230 p.

OLIVEIRA, R.R.; LIMA, D.F.; DELAMÔNICA, P.; SILVA, R.F.; TOFFOLI, D.D.G. Roça Caiçara: Um Sistema "primitivo" auto-sustentável. Ciência Hoje, Rio de Janeiro, v. 18, n. 104, p. 45-51, 1994.

PARRY, M.L.; CANZIANI, O.F.; PALUTIKOF, J.P.; VAN DER LINDEN, P J.; HANSON, C.E. (Eds.). Climate Change 2007: Impacts, Adaptation and Vulnerability. Contribution of Working Group II to the Fourth Assessment Report of the Intergovernmental Panel on Climate Change. Cambridge: Cambridge University $\quad$ Press, $2007 . \quad 976 \quad$ p. http://www.ipcc.ch/publications and data/publications ipcc fourth assessment report wg2 report impacts adaptation and vulnerability.htm

PEREIRA, M.A.; CAMPOS, W.G. Pagamento por serviços ambientais aliando conservação e Ecoturismo. Revista Brasileira de Ecoturismo, São Paulo, v.2, n.3, p. 255-272, 2009.

PICKERING C.M.; HILL W. Impacts of recreation and tourism on plant biodiversity and vegetation in protected areas in Australia. Journal of Environmental Management, London, Vol. 85, n. 4, p. 791-800. 2007.

PIMENTEL, H. U. A ambigüidade da moral colonial: casamento, sexualidade, normas e transgressões. Universitas FACE, Brasília, v. 4, n. 1/2, p. 29-63, 2007. 
PINTO, L.P.; BEDÊ, L.; PAESE, A.; FONSECA, M.; PAGLIA, A.; LAMAS, I. Mata Atlântica Brasileira: Os desafios para conservação da Biodiversidade de um Hotspot Mundial. In: ROCHA, C. F. D.; BERGALLO, H. G.; SLUYS, M. V.; ALVES, M. A. S. (Org.). Biologia da Conservação: Essências. São Carlos: RiMa, 2006. p. 91-118.

PRIMACK, R.B.; RODRIGUES, E. Biologia da conservação. Londrina: Editora Midiograf, 2001. 327 p.

RAMCHURJEE, N.A. Impacts of ecotourism in Rajiv Gandhi National Park (Nagarhole), Karnataka. Environment, Development and Sustainability. Oxford: v. 15, n. 6, p 1517-1525. 2013.

RAUP, D.; SEPKOSKY, J. Mass extinctions in the marine fossil record. Science, Washington,v. 215, n. 4539, p. 1501-1503, 1982.

REDFORD, K.H. The empty forest. Bioscience, California, v. 42, n. 6, p. 412422, 1992.

RIBEIRO, M.C.; METZGER, J.P.; MARTENSEN, A.C.; PONZONI, F.J.; HIROTA, M. M. The Brazilian Atlantic Forest: How much is left, and how is the remaining forest distributed? Implications for conservation. Biological Conservation, Barking, v. 142, n. 6, p. 1141-1153, 2009.

RODRIGUES, G.B.; AMARANTE-JUNIOR, O.P. Ecoturismo e conservação ambiental: contextualizações gerais e reflexões sobre a prática. Revista Brasileira de Ecoturismo, São Paulo, v. 2, n. 2, p. 142-159, 2009.

RUDD, M.A. Scientists' Opinions on the Global Status and Management of Biological Diversity. Conservation Biology, Malden, v.25, n.6, p. 1165-1175. 2011.

SANTOS, A.A. Parques Nacionais Brasileiros: relação entre Planos de Manejo e a atividade ecoturística. Revista Brasileira de Ecoturismo, São Paulo, v. 4, n. 1, p. 141-162. 2011.

SANTOS, B.A.; PERES, C.A.; OLIVEIRA, M.A.; GRILLO, A.S.; ALVES-COSTA, C. P.; TABARELLI, M. Drastic erosion in functional attributes of tree assemblages in Atlantic forest fragments of northeastern Brazil. Biological Conservation, Barking, v. 141, p. 249-260, 2008.

SAUNDERS, D.A.; HOBBS, R.J.; MARGULES, C.R. Biological consequences of ecosystem fragmentation: a review. Conservation Biology, Malden, v.5, p.18-32, 1991.

SCARANO, F.R. Prioridades para conservação: a linha tênue que separa teorias e dogmas. In Rocha C.F.D et al. (Ed.). Biologia da Conservação: essências. São Carlos: Editora Rima, 2006. p. 23-39.

SECRETARIADO DA CONVENÇÃO SOBRE DIVERSIDADE BIOLÓGICA, PANORAMA DA BIODIVERSIDADE GLOBAL 3, Brasília, Ministério do Meio Ambiente, Secretaria de Biodiversidade e Florestas (MMA), 2010., 94 p.

SEKERCIOGLU, C.H. Impacts of birdwatching on human and avian communities. Environmental Conservation, Cambridge, v. 29, n. 3, p. 282289, 2002.

SHAFFER, M.L. Minimum population sizes for species conservation. BioScience, California, v. 31. n. 2. p. 131-134, 1981.

SINAY, L. Modelling and forecasting cultural and environmental changes. 
(PhD Thesis), 282 p. School of Natural and Rural Systems Management, The University of Queensland, 2007.

SNUC. Sistema Nacional de Unidades de Conservação. Lei. N9.985, de 18 de julho de 2000. Disponível em <http://www.planalto.gov.br/ccivil 03/leis/L9985.htm>. Acesso em: 25 set. 2011.

SOULÉ, M.E. (Ed.). Conservation Biology: the science of scarcity and diversity. Massachusetts: Sinauer Assoc., 1986, 584 p.

SOULÉ, M.E. What is Conservation Biology? Bioscience, California, v. 35, p. 727-734, 1985.

STEHMANN, J.R.; FORZZA, R.; SALINO, A.; SOBRAL, M.; COSTA, D.P.; KAMINO, L.H.Y. Plantas da Floresta Atlântica. Rio de Janeiro: Jardim Botânico do Rio de Janeiro, 2009. 500 p.

TERBORGH, J.; SCHAIK, C. van; DAVENPORT, L.; RAO, M. (Org.). Tornando os parques eficientes: estratégias para a conservação da natureza nos trópicos. Curitiba: Ed. UFPR / Fundação O Boticário, 2002, 518 p.

THOMAS, C.D. Climate, climate change and range boundaries. Diversity and Distributions, Stellenbosch, v. 16, n. 3, p. 488-495, 2010.

TYRVÄINEN, L.; VÄÄNÄNEN, H. The economic value of urban forest amenities: an application of the contingent valuation method. Landscape and Urban Planning, Amsterdam, v. 43, n. 1-3, p. 105-118, 1998.

ULRICH, R.S. Human responses to vegetation and landscapes. Landscape and Urban Planning, Amsterdam, v. 13, p. 29-44, 1986.

UN, $2011 . \quad$ Disponível em <http://www.un.org/apps/news/story.asp?NewsID=40257>. Acesso em: 12 dez. 2011.

VAN DYKE, F. Conservation Biology: Foundations, Concepts, Applications. US: Springer Verlag, 2008, 354 p.

WALL, G. Is ecotourism sustainable? Environmental Management, London, v. 21, n. 4, p. 483-491, 1997.

WALTER, P.G. Theorising visitor learning in ecotourism. Journal of Ecotourism. v. 12, n. 1, p. 15-32. 2013.

WANG, G.; INNES, J.L.; WU, S. W.; KRZYZANOWSKI, J.; YIN, Y.; DAI, S.; ZHANG, X.; LIU, S. National park development in China: Conservation or commercialization? Ambio: Kungl: v. 41, n. 3, p. 247-261. 2012.

WATANABE, S. (Ed.). Glossário de ecologia. ACIESP, São Paulo. n. 57. 1987. $271 \mathrm{p}$.

WEAVER, D.B.; LAWTON, L. 2007. Twenty years on: The state of contemporary ecotourism research. Tourism Management, v. 28, p. 1168-1179, 2013.

WHITMORE, T.C. An introduction to Tropical Rain Forests. New York: Oxford University Press, 1993, 224 p.

WHITTAKER, R.J.; WILLIS, K.J.; FIELD, R. Scale and species richness: towards a general, hierarchical theory of species diversity. Journal of Biogeography, Oxford, v. 28, p. 453-470, 2001. 
YANG, J.; ZHAO, L.; MCBRIDE, J.; GONG, P. Can you see green? Assessing the visibility of urban forests in cities. Landscape and Urban Planning, Amsterdam, v. 91, p. 97-104, 2009.

ZAÚ, A.S. Ecologia da paisagem no planejamento territorial. Floresta e Ambiente, Seropédica, v. 4, p. 98-103, 1997.

ZAÚ, A.S. Fragmentação da Mata Atlântica. Floresta e Ambiente, Seropédica, v. 6 , n. 1, p. 160-170, 1998.

ZAÚ, A.S. Composição, estrutura e efeitos de bordas lineares na comunidade arbustiva-arbórea de um remanescente urbano de Mata Atlântica no sudeste do Brasil. 2010. 229 f. Tese (Doutorado em Botânica). - Instituto de Pesquisas Jardim Botânico do Rio de Janeiro, Escola Nacional de Botânica Tropical, Rio de Janeiro, 2010.

\section{Agradecimentos}

Agradeço aos coordenadores do II Fórum de Planejamento Turístico da Universidade Federal do Estado do Rio de Janeiro - 2011, que resultou na concepção deste artigo, especialmente à Laura Sinay. Agradeço ainda à Rogério Oliveira e Aline Machado, pela leitura crítica de versão preliminar deste texto; à Maria Isabel Sigiliano e Betina Kozlowsky Suzuki pela revisão do abstract; e à Gabriela Akemi Oda, Vinícius Costa, Allan Lopes, Erika Almeida pela organização das referências.

\section{Notas}

${ }^{1}$ A Avaliação Ecossistêmica do Milênio (MA) foi solicitada pela ONU em 2000. O objetivo do MA foi avaliar as consequências das alterações antrópicas nos ecossistemas em relação ao bem-estar humano e apresentar as bases científicas para a ação necessária para melhorar a conservação e o uso sustentável dos sistemas, bem como a contribuição destes para o bem estar. A MA tem envolvido o trabalho de mais de 1.360 especialistas em todo o mundo. Suas descobertas, contidas em cinco volumes técnicos e seis relatórios de síntese, proporcionam uma apreciação do estado-da-arte-científica, uma avaliação das condições e tendências de ecossistemas do mundo, dos serviços ambientais que os mesmos proporcionam (como água potável, alimentos, produtos florestais, controle de inundações e recursos naturais) e opções para restaurar, conservar ou melhorar 0 uso sustentável dos ecossistemas (MILLENNIUM ECOSYSTEM ASSESSMENT, 2005).

${ }^{2}$ Capacidade de um sistema suportar perturbações ambientais, de manter sua estrutura e padrão geral de comportamento quando modificada sua condição de equilíbrio. Sistemas resilientes são aqueles que podem retornar a uma condição de equilíbrio após modificações consideráveis (WATANABE, 1987).

${ }^{3}$ Espécie que originalmente não ocorre na localidade, podendo ser até mesmo uma espécie de outro continente, o que pode fazer que a mesma apresente desequilíbrios populacionais e desequilíbrios na comunidade devido à ausência de outras espécies que co-evoluiram nas relações de competição, predação e herbivoria, patógenos etc.

${ }^{4}$ No Estado do Rio de Janeiro a cobertura atual corresponde a 19,59\% da Mata Atlântica original (FUNDAÇÃO SOS MATA ATLÂNTICA e INSTITUTO NACIONAL DE PESQUISAS ESPACIAIS, 2010). 
${ }^{5}$ A população em áreas urbanas, respectivamente no mundo e no Brasil, corresponde hoje a 50,6\% e $86,5 \%$. Em 30 anos corresponderá a 64,7\% e 92,4\% (UN, 2011).

${ }^{6}$ Existe uma crítica justificada de conservacionistas contra os "parques de papel" (senso TERBORGH et al., 2002). Ou seja, aqueles que não apresentam estrutura fundiária definida, equipe, infraestrutura e planos de manejo adequados à gestão eficiente da unidade de conservação, ou ainda não apresentam suporte legal e social dos países e localidades nos quais esses "parques" estão alocados.

${ }^{7}$ SNUC, 2000. Art. 35. Os recursos obtidos pelas unidades de conservação do Grupo de Proteção Integral mediante a cobrança de taxa de visitação e outras rendas decorrentes de arrecadação, serviços e atividades da própria unidade serão aplicados de acordo com os seguintes critérios: I - até cinquenta por cento, e não menos que vinte e cinco por cento, na implementação, manutenção e gestão da própria unidade; II - até cinquenta por cento, e não menos que vinte e cinco por cento, na regularização fundiária das unidades de conservação do Grupo; III - até cinquenta por cento, e não menos que quinze por cento, na implementação, manutenção e gestão de outras unidades de conservação do Grupo de Proteção Integral.

André Scarambone Zaú: Universidade Federal do Estado do Rio de Janeiro, Rio de Janeiro, RJ, Brasil.

E-mail: andrezau@unirio.br

Link para o currículo Lattes: http://lattes.cnpq.br/9561885200662079

Data de submissão: 31 de outubro de 2012

Data de recebimento de correções: 08 de março de 2014

Data do aceite: 27 de março de 2014

Avaliado anonimamente 